\title{
A STUDY OF VARIATION IN MEDIAN NERVE FORMATION IN
} CADAVERS

\author{
Pampi Ranjan ${ }^{1}$, Pritha S. Bhuiyan ${ }^{2}$.
}

${ }^{*}$ Senior Resident, Department of Anatomy, 2nd Floor, College Building, Seth G.S. Medical College and KEM Hospital, Parel, Mumbai, Maharashtra, India.

2 Professor and Head, Department of Anatomy, 2nd Floor, College Building, Seth G.S. Medical College and KEM Hospital, Parel, Mumbai, Maharashtra, India.

\section{ABSTRACT}

Background: Median nerve is the nerve of the flexor compartment of forearm. Variations in the formation of median nerve is common. Knowledge of such variations is important for the evaluation of nerve injuries in upper limb region.

Materials \& methods: The study was done on 36 formalin fixed cadavers (72 upper limbs). The pattern of formation of median nerve in axilla was observed after performing meticulous dissection.

Observations: Out of total 72 specimens, 67 upper limbs (93.06\%) showed formation of median nerve by the fusion of two roots while in the remaining five specimens (6.94\%), median nerve was formed by three roots. Out of those five specimens, all of them showed median nerve formation by two medial and one lateral root. Out of the total 72 specimens, three specimens showed communication between median and musculocutaneous nerve in the arm region and two specimens showed absence of musculocutaneous nerve.

Conclusion: This study has described the normal way of formation of median nerve as well as the variations in its roots of formation.

KEY WORDS: Median nerve, Lateral \& medial root, Roots of formation

Corresponding Author: Dr. Pampi Ranjan, Department of Anatomy, 2nd Floor, College Building, Seth G.S. Medical College and KEM Hospital, Parel, Mumbai-400012, Maharashtra, India.

E-Mail: pmprnjn992@gmail.com

Access this Article online

Quick Response code

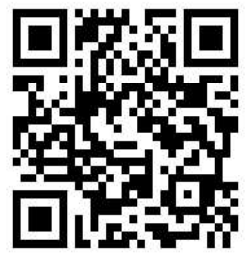

DOI: $10.16965 /$ ijar.2020.111
Journal Information

International Journal of Anatomy and Research

RG Journal ISSN (E) 2321-4287 | ISSN (P) 2321-8967

Impact: 0.21* https://www.ijmhr.org/ijar.htm

DoI-Prefix: https://dx.doi.org/10.16965/ijar

Article Information

Received: 27 Jan 2020

Peer Review: 28 Jan 2020

Revised: None
Accepted: 20 Feb 2020

Published (O): 05 Mar 2020

Published (P): 05 Mar 2020

\section{INTRODUCTION}

Median nerve being a nerve of upper limb innervates the muscles of flexor aspect of forearm as well as the thenar muscles of palm. During its course, it shows a lot of variations. One of the important variations being the number of roots of formation. Median nerve is generally formed in the axilla by two roots medial \& lateral root, coming from the medial and lateral cord of brachial plexus respectively. Along with the variation in its formation, communication of median nerve with other nerves are also common [1].

Variations in the number of roots of formation of median nerve are clinically important to interpret the presentation of clinical signs in cases of nerve injury. Communication of median nerve with musculocutaneous nerve has got an embryologic basis and also significant, both surgically and clinically, in the interpretations of nerve injuries [2]. 


\section{MATERIALS AND METHODS}

The study was conducted on upper limbs of 36 formalin embalmed cadavers in a tertiary care hospital of Maharashtra. Due permission was obtained from the Ethics Committee of the Institution.

All the upper limb specimens were dissected conventionally following Cunningham's practical manual and the pattern of median nerve formation in axilla was observed. Injured and severed specimens were excluded from the study.

Fig. 1: Illustration showing three roots of formation of median nerve; LR: Lateral root; MR: Medial root; MN: Median nerve; AA: Axillary artery;

MCN: Musculocutaneous nerve; P: Proximal; D: Distal; M: Medial; L: Lateral.

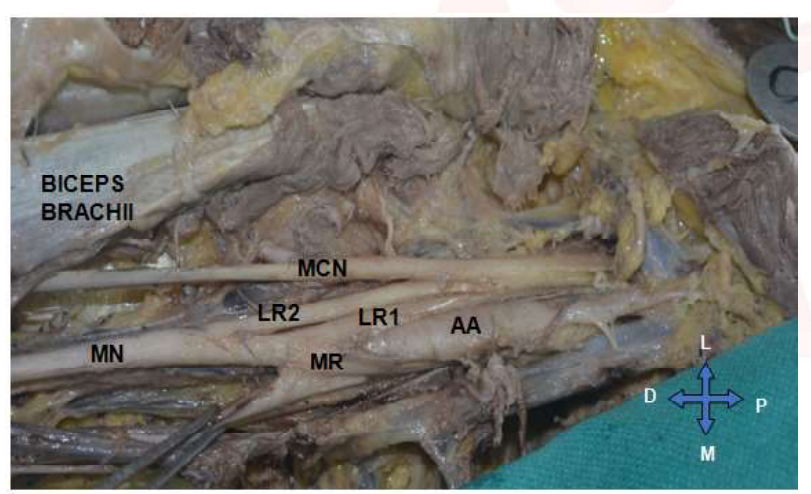

Fig. 2: Illustration showing absence of musculocutaneous nerve (MCN); Median nerve(MN) supplying muscle of anterior compartment of arm.

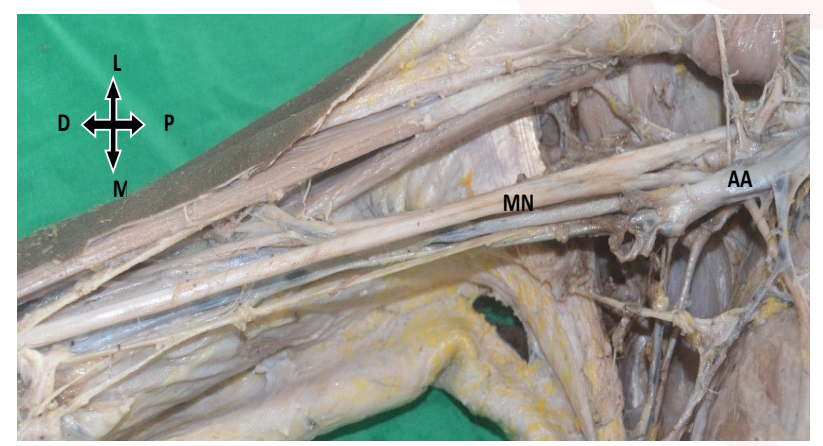

Fig. 3: Illustration showing communication between median nerve (MN) and musculocutaneous nerve (MCN).

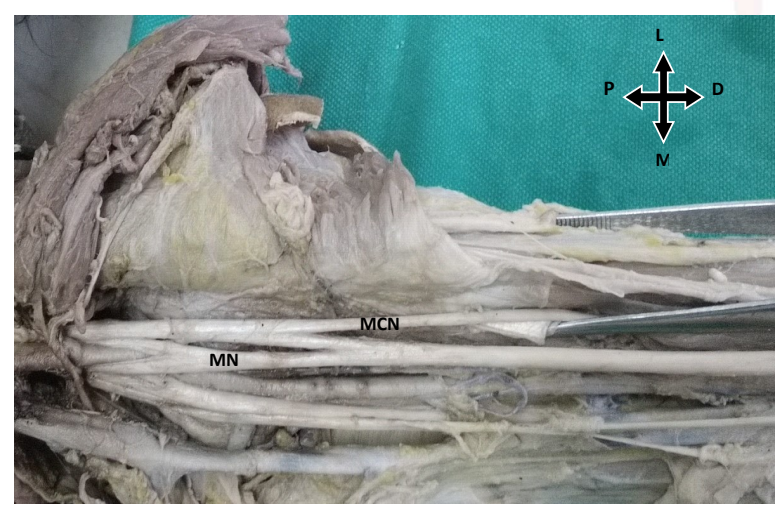

\section{RESULTS}

Out of total 72 upper limb specimens (36 left and 36 right side), 67 specimens (93.06\%) showed the normal pattern of formation of median nerve from two rootsi.e. one medial and one lateral root while in the remaining five specimens (6.94\%), median nerve was formed by three roots. Out of these five specimens, all of them showed two lateral and one medial root of formation. Out of 72 specimens, three specimens showed communication between median and musculocutaneous nerve in the arm region while two specimens showed absence of musculocutaneous nerve and in those specimens, median nerve was observed to supply the corachobrachialis and biceps brachii muscle in the arm region.

Table 1: Comparison of studies showing roots of formation of median nerve.

\begin{tabular}{|c|c|c|c|c|}
\hline Study & Year & Country & Specimens & $\begin{array}{c}\text { Result } \\
\text { (in \%) }\end{array}$ \\
\hline Chouhan et al [8] & 2002 & India & Case study & - \\
\hline Sachdeva K. et al [9] & 2011 & India & Case study & - \\
\hline B. Caetano et al [4] & 2016 & Brazil & 40 & 25 \\
\hline Present study & $\mathbf{2 0 1 8}$ & India & $\mathbf{7 2}$ & $\mathbf{4}$ \\
\hline
\end{tabular}

Table 2: Studies showing communication between median nerve and musculocutaneous nerve.

\begin{tabular}{|c|c|c|c|c|}
\hline Study & Year & Country & $\begin{array}{c}\text { Material for } \\
\text { study }\end{array}$ & Result (in \%) \\
\hline Budhiraja et al [1] & 2011 & India & Cadaver (196) & $\begin{array}{c}74.03 \text { (2 roots) } \\
22.47 \text { (3 roots) } \\
3.57 \text { (4 roots) }\end{array}$ \\
\hline lyer et al [2] & 2016 & India & Cadaver (98) & $\begin{array}{c}95.92 \text { (2 roots) } \\
4.08 \text { (3 roots) }\end{array}$ \\
\hline Taib et al [3] & 2016 & Malaysia & Cadaver (44) & $\begin{array}{c}2.27 \text { (1 root) } \\
68.18 \text { ( } 2 \text { roots) } \\
27.27 \text { (3 roots) } \\
2.27 \text { (4 roots) }\end{array}$ \\
\hline Present study & 2018 & India & Cadaver (72) & $\begin{array}{c}93.06 \text { ( } 2 \text { roots) } \\
6.94 \text { (3 roots) }\end{array}$ \\
\hline
\end{tabular}

\section{DISCUSSION}

Many studies have been performed over the formation pattern of median nerve in cadavers. Budhiraja et al [1] (2011) observed in 196 cadavers that $74.03 \%$ specimens showed two roots of formation of median nerve while $22.47 \%$ showed three roots of formation. The present study is comparable with the study done by lyer et al [2] (2016) which is done on 98 cadavers in which $95.92 \%$ specimens showed two roots of formation of median nerve while $4.08 \%$ specimens showed three roots of formation of 
median nerve.

Knowledge of the communication between median and musculocutaneous nerve is important in the assessment and management of peripheral nerve lesions of upper limb. Injury of the musculocutaneous nerve proximal to the communication may manifest as the carpal tunnel syndrome or as the clinical features related with median nerve injuries. This anatomical variation should be considered during the neurotization procedure of the musculocutaneous nerve for the restoration of elbow flexion.

Caetano et al [4] (2016) observed in a study conducted on 40 specimens of upper limb that 10 specimens showed communication between median and musculocutaneous nerve. In the present study out of 72 specimens, four upper limbs showed communication between median and musculocutaneous nerve.

Absence of musculocutaneous nerve is rarely seen in some specimens. Musculocutaneous nerve supplies the important flexor muscles of the elbow joint and its absence may provide an explanation for the cases where it is impossible to flex the forearm due to median nerve injury. A case study done by Song et al [5] (2003) showed absence of musculocutaneous nerve on the left side of the arm. In the present study, out of total 72 specimens, two specimens showed absence of the nerve.

Le minor JM [6] (1992) classified communication between median and musculocutaneous nerve as: Type I - No communication between musculocutaneous nerve and median nerve. Type II - Fibres of medial root of median nerve pass through musculocutaneous nerve and join the median nerve in the middle of the arm. Type III - Lateral root fibres of median nerve pass along the musculocutaneous nerve and after some distance, leave it to form lateral root of median nerve. Type IV - Musculocutaneous nerve fibres join lateral root of median nerve and after some distance the musculocutaneous nerve arise from median nerve. Type $V$ - Musculocutaneous nerve is absent and entire fibres of musculocutaneous nerve pass through the lateral root and fibres to the muscles supplied by musculocutaneous nerve branch out directly from median nerve.

Int J Anat Res 2020, 8(1.3):7395-98. ISSN 2321-4287
On the basis of embryological development, anomalous formation pattern of the median nerve can be explained. The upper limb buds lie opposite the lower five cervical and upper two thoracic segments. As soon as the buds form, the ventral primary rami of the spinal nerve penetrate into the mesenchyme of limb bud. Immediately, the nerves enter the limb bud and they establish intimate contact with the differentiating mesodermal condensations. The early contact between nerve and muscle cells is a pre-requisite for their complete functional differentiation [7].

Several signalling molecules and transcription factors have been identified, which induce the differentiation of the dorsal and ventral motor horn cells. Misexpressions of any of these signalling molecules can lead to abnormalities in the formation and distribution of particular nerve fibres.

\section{CONCLUSION}

In the axilla, procedures such as the excision of enlarged lymph nodes or the axillary nerve block, requires a clear-cut anatomical knowledge of median nerve. Variation in the number of roots of median nerve may be missed during the surgical procedures. Abnormal communications between median and musculocutaneous nerve may be a reason for the abnormal presentation during nerve injuries especially carpal tunnel syndrome.

\section{Conflicts of Interests: None}

\section{REFERENCES}

[1]. Budhiraja V, Rastogi R, Asthana AK. Anatomical variations of median nerve formation: embryological and clinical correlation. J. Morphol. Sci 2011; 28(4): 283286.

[2]. Iyer PB, Rajgopal L. Variations in the formation of the median nerve. National Journal of Integrated Research in Medicine. 2016 May 1;7(3):17-20.

[3]. Taib CM, Hassan SN, Esa N, Moklas MM, San AA. Anatomical variations of the median nerve formation, distribution and possible communication with other nerves in preserved human cadavers. Folia Morphologica. 2017; 76(1): 38-43.

[4]. Caetano EB, Vieira LA, Cavalheiro CS, Rezuk FM, Almargo MA, Caetano MF. Anatomic study of the nervous communication between the median and musculocutaneous nerve. Acta orthopedica brasileira. 2016 Aug; 24(4): 200-3. 
[5]. Song WC, Jung HS, Kim HJ, Shin C, Lee BY, Koh KS. A variation of the musculocutaneous nerve absent. Yonsei medical journal. 2003 Dec 1; 44(6): 1110- 3.

[6]. Le Minor, J.M: A rare variant of the median and musculocutaneous nerves in man. Achieves Anatomy Histology Embryology. 1992;73: 33-42.

[7]. TW Saddler. Langman's Medical Embryology. 13th Ed. Philadelphia, Wolter Kluwer. 2015: 166-170.
[8]. Chauhan R, Roy TS. Communication between the median and musculocutaneous nerve - a case report. J Anat Soc India. 2002; 51(1):72-5.

[9]. Sachdeva K, Singla RK. Communication between median and musculocutaneous nerve. J. Morphol. Sci., 2011;28(4):246-249.

How to cite this article:

Pampi Ranjan, Pritha S. Bhuiyan. A STUDY OF VARIATION IN MEDIAN NERVE FORMATION IN CADAVERS. Int J Anat Res 2020;8(1.3):7395-7398. DOI: 10.16965/ijar.2020.111 